\section{Commentary on "Complex Variability within the THCA and CBDA Synthase Genes in Cannabis Species"}

\section{Article Commentary}

We read with great interest the 2016 publication by Allen et al. on variation in THCA and CBDA synthase DNA sequences from seized marijuana samples [1]. We wish to comment on the question of designing a molecular assay to accurately predict THCA content in Cannabis plants. This is an especially important issue in light of current regulatory policy and the expanding Cannabis economy.

In concluding that there is "no strong correlation between genotype and chemotype for THCA", the authors appear to have overlooked the possibility that $C B D A$ synthase rather than THCA synthase is responsible for the major chemotypic difference between drug-type and non-drug-type Cannabis. All five drug-type samples for which $C B D A$ synthase sequences are shown in Figure 4 share a four-base (nonsense-inducing) deletion at position 153 compared to sequences encoding a functional enzyme. This finding is consistent with the main conclusion of Weiblen et al., namely in that plants lacking functional CBDA synthase produce primarily THCA [2]. We based our conclusion on the fact that THCA synthase and CBDA synthase compete for a common substrate, CBGA. Drug-type, intermediate and non-drug-type plants are widely recognized in the literature according to the ratio of THCA:CBDA [3].

Weiblen et al. showed that the presence or absence of alleles bearing the $C B D A$ synthase sequence deletion is perfectly correlated

\section{Journal of \\ Forensic Investigation}

\section{George D. Weiblen* and Jonathan P. Wenger \\ Department of Plant and Microbial Biology, University of Minnesota, Saint Paul, USA}

*Address for Correspondence

George D. Weiblen, Department of Plant and Microbial Biology, University of Minnesota, Saint Paul, MN 55108, USA, Tel: 612624-3461; E-mail: gweiblen@umn.edu

Submission: 29 November, 2016

Accepted: 20 December, 2016

Published: 28 December, 2016

Copyright: () 2016 Weiblen GD, et al. This is an open access article distributed under the Creative Commons Attribution License, which permits unrestricted use, distribution, and reproduction in any medium, provided the original work is properly cited.

with the three major classes of Cannabis chemotypes. We find it misleading to cast doubt on a diagnostic assay for major differences in THCA content when genotypes may be scored by Sanger sequencing of PCR amplicons spanning the CBDA synthase deletion.

\section{References}

1. Allen LN, Jun Fu, Pritchard JK, Wellendorf R, Allen RW (2016) Complex Variability within the THCA and CBDA synthase genes in Cannabis species. J Forensic Investigation 4: 7.

2. Weiblen GD, Wenger JP, Craft KJ, EISohly MA, Mehmedic Z, et al. (2015) Gene duplication and divergence affecting drug content in Cannabis sativa. New Phytol 208: 1241-1250.

3. de Meijer EP, Bagatta M, Carboni A, Crucitti P, Moliterni VM, et al. (2003) The inheritance of chemical phenotype in Cannabis sativa L. Genetics 163 : 335-346. 